\title{
Engaging Health Care Employers to Develop an AS in Health Sciences Degree With Stackable Credentials
}

\author{
Stacia Reader \\ Bronx Community College \\ Seher Atamturktur \\ Bronx Community College \\ Gregory Cobb \\ Bronx Community College
}

\begin{abstract}
Many pre-clinical nursing students at Bronx Community College (BCC) of the City University of New York fail to sustain momentum, resulting in derailed or prolonged paths to graduation. To help increase students' chances of graduating, and finding careers within the health professions, BCC is developing a new Associate of Science (AS) in Health Sciences with embedded "stackable" certifications. This paper will describe how faculty hosted a round table discussion with employers to obtain information regarding growing health sectors and needed skills, the salient themes that arose from the event, and how these findings are being used to create the degree's curriculum.
\end{abstract}

Keywords: curriculum development, health sciences, community college, stackable credentials, employer engagement

\section{INTRODUCTION}

More than $40 \%$ of undergraduates attend a community college, yet many of these students, especially those from low-income and minority backgrounds, struggle to complete a degree (Community College Research Center, 2021). The six-year completion rate for students who enrolled in public two-year institutions in 2014 was $40.2 \%$ compared to $67.4 \%$ for four-year public institutions. During this same time period the completion rates for Hispanic and African American students enrolled in two-year institutions declined, while the completion rates for Hispanic and African American students at four-year institutions increased (Causey et al., 2020). In addition, COVID-19 has augmented the existing challenges and created new ones for many community colleges. According to the National Student Center Clearing House Research Center (2020), two-year public institutions saw a 9.5\% decline in their enrollment during the Fall 2020 semester while four-year public institutions saw a 1.9\% for decline in their enrollment.

Health professions and related programs are the most popular areas of study among associate degree seeking students (National Center for Education Statistics, 2019) and nursing is a common career path for many two and four-year college students (Haynie, 2015). For instance, at Hunter College of the City 
University of New York (CUNY), one fifth of its entering and transfer students are prospective nursing students (Mintz, 2020). This is understandable, given that jobs in the health care sector are in demand, with a projected growth rate of $18 \%$ by 2026 (Martiniano \& Moore, 2018). Associate degree nursing (ADN) programs are very selective as well (Trofino, 2013). Most of the students who are accepted into these programs eventually go on to obtain a Bachelor of Science in Nursing (BSN) by enrolling in 12-18-month completion programs (Buerhause et. al., 2016). Thus, ADN programs require students to maintain a high GPA in perquisite courses for admission into their programs and even qualified students may be waitlisted because of limited enrollment capacity (Haynie, 2015).

Although countless students aspire to become nurses, many college students begin their college careers with little understanding of how their current major is linked to broader career options (Gardenhire-Cooks, Collado, \& Ray, 2006). They are likely to be underprepared for rigorous coursework of pre-clinical courses and lack knowledge of the nursing programs' admission processes. Given the array of options available to them, students often struggle with making choices and end up selecting a major, such as pre-clinical nursing, that may not fit with their personality and/or academic abilities, which could ultimately lead to them drop out of school (Jenkins and Cho, 2012; Scott and-Clayton, 2011). Community college students, especially, are more likely to be first generation, and come from low-income families and historically underrepresented groups, and therefore may lack the nuanced information, robust social networks and guidance they need in making education and career decisions (Baker et al, 2017). With this in mind, BCC applied for and received funding in 2019 from Graduate NYC, an organization with a focus on increasing the number of college students who earn degrees (Graduate NYC, 2019), to develop an AS in Health Sciences degree.

The activities in the grant funded project entitled, "The Health Careers Pathway Project", include developing an AS in Health Sciences degree, implementing health careers and majors information sessions for students, and providing enhanced training for advisors around health careers and majors. The overarching focus of these activities is to provide a streamlined and career-focused pathway to graduation for the significant number of BCC students, who, despite having entered the College with the intent to pursue an Associate of Applied Science (AAS) in Clinical Nursing, do not have a true understanding of the profession and/or cannot meet the program's highly stringent grade requirements. For many of these students, although nursing may not be the right occupation, a career in the health sector is still in alignment with their professional goals and interests. The new degree program, which will include embedded "stackable" certifications, could be the means to an accelerated path to graduation and meaningful, selfsustaining careers within the health professions for many of our students. The creation of this new degree is also in line with BCC's most recent Academic Master Plan, which recommended the development of an AS in Health Sciences Degree at the College. (Ott, 2018).

Our plan to develop an AS in Health Sciences, which accommodates a wide range of students interested in health careers, reflects nationwide trends. Many colleges are seeing the value in providing an academic home for students who matriculate with the intent to pursue a clinical nursing degree but are ultimately unprepared for the academic rigors of the program. For example, the Borough of Manhattan Community Colleges of CUNY offers an AS in Science for Health Professions (n.d.), the Community College of Baltimore County offers an Allied Health, Associate of Applied Science (2021) with embedded stackable credentials, and Rogue Community College offers a Basic Health Care Certificate (2021) with a diverse range of specialty track electives to help guide students toward completion of an additional degree or certificate. Moreover, the creation this degree is in alignment with the guided pathways approach, which is the idea that college students are more likely to persist and complete a degree in a timely fashion if they choose a program and develop an academic plan early on, have a clear road map of the courses they need to complete a credential, and receive guidance and support to help them stay on plan. According to Columbia University's Community College Research Center, a growing number of colleges and universities are implementing guided pathways reforms and evidence from these institutions, suggests that more coherent and clearly structured pathways are helping improve student outcomes (Bailey et al., 2015).

The degree also addresses the nation's urgent and growing need for talent. A need, according to the Lumina Foundation's initiative A Stronger Nation: Learning Beyond High School Builds American Talent (2019), that will only be met if many more people earn college degrees, workforce certificates and high- 
quality credentials. The development of an AS degree in Health Sciences, which embeds stackable certifications that align directly with employer needs, supports Lumina's initiative. The Bronx has the largest proportion of unemployed residents of any county in the state of New York (New York State Department of Labor, 2020). The COVID-19 pandemic has only worsened the unemployment rate (Hu et al, 2020) and BCC is a resource for the future of Bronx residents. Educational opportunity, especially beyond high school, provides an important pathway not only to employment but higher incomes and the reduction of social inequality (Lumina Foundation, 2019). Further, the need to train Bronx residents for health care jobs has never been greater. The Bronx has been identified as a Health Professional Shortage Area and a Medically Underserved Area and remains underserved in primary care services, which has a significant impact on the health status of its residents and demonstrates an ongoing need for training a diverse and skilled health care workforce (U.S. Department of Health and Human Services, 2020). In addition, New York State recently implemented the Delivery System Reform Incentive Payment (DSRIP). This is the main mechanism by which New York State will implement the Medicaid Redesign Team Waiver Amendment. DSRIP's purpose is to restructure the health care delivery system in New York, which aims to reduce avoidable hospital admissions by $25 \%$ by building a system that is coordinated and community based with a focus on treatment, wellness and disease prevention (New York State Department of Health, 2020). New York is concentrating on prevention, thus more jobs in the realm of community health are likely to be supported by the health care sector.

The purpose of this paper is to describe how BCC faculty and staff engaged with local health care employers and organizations to develop the curriculum for an AS in Health Sciences degree. By engaging with employers, institutions can better develop programs that are responsive to the needs of local industry and ensure that students who enter into programs achieve industry credentials and skills, and secure selfsustaining employment (Bond, 2013). The following topics will be discussed, 1) the implementation process for an employer round table session, 2) the salient themes that arose during the event and 3) how the findings are being used to create the curriculum for a degree that is informed by local workforce needs.

\section{METHODS}

\section{Setting}

BCC is a federally designated Hispanic Serving Institution and offers more than 30 academic programs. The College serves over 10,500 students annually, 61\% of whom are Hispanic/Latino, 33\% AfricanAmerican/Black, 4\% Asian, and 2\% White. More than half (56\%) are women. Students hail from more than 100 countries and 55\% are first generation college students. Eighty-four percent of students are estimated to be low-income Even with financial assistance, many BCC students struggle to meet their daily needs: $40 \%$ come from households that earn less than $\$ 15,000$ annually; $37 \%$ worry about having enough to eat and $68 \%$ worry about housing costs. BCC's student population is reflective of the Bronx communitycongressional district 15-where our nationally landmarked campus is located. Here, the unemployment rate is $13.7 \% 5$ (compared to New York City's overall rate of $4.2 \% 6$ ); the annual median household income is $\$ 26,096$ and 39.5\% live below the poverty line (Bronx Community College, 2020)

\section{Selection Criteria and Participant Recruitment}

BCC faculty and staff, including those from the BCC's Office of Career and Transfer Services and the Department of Workforce and Economic Development, consulted with each other, and the staff at CUNY's Office of the University Dean for Health and the Human Services, to create a contact list of about 25 local health care sector employers to invite to an employer round table session. An invitation was created and emailed individually to each person on the contact list six week prior to the event. The email invited attendees to the event and informed them that the College was creating a new associate's degree in health sciences with embedded stackable credentials. We wrote that we hoped the curriculum would provide a strong academic and practical foundation for students interested in pursuing careers in health care. We emphasized that we saw great potential to create a local pipeline into the allied health professions, and would highly value their input on the needed skills and credentials of the local healthcare workforce. We 
also stressed that we wanted the curriculum for the new degree to reflect the needs of health care employers in the Bronx. As incentives, we closed by mentioning that the event would also be a great opportunity to network and a light breakfast would be served. For those who did not respond right away, follow-up emails and phone calls were made encouraging participants to attend.

A total of thirty people attended the event, including nineteen staff and faculty from BCC and CUNY Central. Eleven leaders from various health care organizations, nonprofit social agencies, a government entity, a health care union, an accountable care organization and two Performing Provider Systems (PPSs) attended the event as well. PPSs are providers that form partnerships with an array of other providers, for example hospitals, health homes, skilled nursing facilities, clinics and Federally Qualified Health Care Centers, behavioral health providers, community-based organizations and others, to carry out DSRIP projects (New York State Department of Health, 2020). See Table 1 for the list of organizations represented at the round table discussion.

TABLE 1

LOCAL HEALTH AGENCIES REPRESENTED AT THE ROUND TABLE

\begin{tabular}{|c|c|}
\hline Organization & Type of Organization \\
\hline Blythedale Children's Hospital & Specialties Children's Hospital \\
\hline $\begin{array}{c}\text { Bronx Accountable Healthcare Network } \\
\text { Aniversity of New York's Bronx Educational } \\
\text { Opportunity Center }\end{array}$ & $\begin{array}{c}\text { A center that provides career and education } \\
\text { services }\end{array}$ \\
\hline Bronx Health Access, BronxCare Health System & Performing Provider Systems \\
\hline Bronx Partners for Healthy Communities & Performing Provider Systems \\
\hline $\begin{array}{c}\text { 1199 Service Employees National Union Training and } \\
\text { Employment Funds }\end{array}$ & $\begin{array}{c}\text { A labor-management fund that provides } \\
\text { comprehensive benefits-including } \\
\text { training-to healthcare industry workers }\end{array}$ \\
\hline Fortune Society & Nonprofit Organization \\
\hline Montefiore Medical Center & Medical Center \\
\hline New York City Department of Health and Mental \\
Hygiene & Local Health Department \\
\hline Nino De La Caridad & Nonprofit Organization \\
\hline Praxis Housing Initiative & Nonprofit Organization \\
\hline
\end{tabular}

\section{Activity}

We hosted a two hour round table session with local health care employers in October 2019. This round table session essentially served as a needs assessment, which is a valuable tool for collecting local market information and broad industry needs. A needs assessment is also an important first step for educators to take when attempting to engage employers in a partnership (Bond, 2013). The session opened with an opportunity for attendees to network for a half hour. Following this, participants were asked to introduce themselves and identify the organization they represented. BCC faculty and staff then gave a brief overview of the project and its goals and some background information on national and local trends regarding AS in health science(s) programs and the impact of DSRIP on the health care system. Next, the presenters described the purpose, which was to obtain employers' feedback regarding growing health care sectors and the needed skills for entry-level positions in the health field to inform the development of the curriculum for the AS in Health Sciences degree at BCC. The remainder of the session was moderated by a faculty member who presented a series of open-ended questions with the audience to elicit group discussion. The following questions were posed to the audience:

1) What are your current entry level job titles?

2) What are the emerging job titles and career opportunities you see in the field? 
3) What skills do you desire most from individuals seeking job opportunities within your agency or organization?

4) What are the current qualifications, experience, and/or academic background that you require for entry level job seekers?

5) Are there any certifications and/or competencies for entry level professionals that you require or see emerging?

6) In your current approach to hiring, what value do you place on having entry level workers with integrated skills such as helping, behavioral and/or clinical?

\section{Data Collection and Analysis}

Two staff members observed the session and took detailed notes. Immediately following the event the staff and program faculty, who were in attendance, held a meeting to debrief and discuss the implementation and outcomes associated with the round table session. The two staff members compared and updated their notes with comments or items that may have missed while taking notes and gave the notes to the core faculty to review. Next, program faculty independently reviewed the notes to identify and code themes. The faculty then held a meeting to establish inter-rater reliability. They compared their independent coding schemes and reached a consensus on the themes of in-demand fields and preferred qualifications for entry level workers.

\section{RESULTS}

Upon completion of data analysis, four main themes emerged, three of these themes were related to growing health care sectors and included care coordination, population health/health administration, and clinical health. Within each of these three themes, employers identified preferred qualifications, needed skills for entry-level workers, and suggestions for curriculum development. Lastly, an additional theme emerged, which was employers' preferred qualifications for all candidates regardless of the type of position they were applying for in the health care sector. These qualifications included some kind of work-related experience (especially customer service experience), knowledge of a second language and communication and professionalism skills

\section{Theme 1: Care Coordination Field}

A majority of participants reported that care coordination is the most in demand and growing field in the Bronx health care sector. Several attendees noted that there are shortages in all care coordination positions. At a basic level, care coordination involves organizing a patient's care activities and sharing that information with all of the individuals who are concerned with a patient's care to achieve safer and more effective care (U.S. Department of Health and Human Services, 2018a). Many of the current entry-level job titles in the field fall under the realm of care management and provider services. Some of the titles include care navigator, care coordinator, patient navigator/advocate, community health worker, outreach and peer specialists. All participants agreed that the minimum education requirement for these entry-level positions is an associate's degree but that experience and education level requirements vary by organization, with some positions needing as much as a master's degree with a clinical license to work with populations who have complex needs. Although an associate degree is the minimum requirement for entry into the field, employers discussed the need for individuals to have real hands-on experience through internships and acquiring certifications or license in specific fields, such as certified nursing assistant, which makes them much more competitive applicants. Participants also mentioned that students should possess an interest in working with patients.

Several attendees noted that care coordination is a complicated and difficult job because of the human and social dynamics involved with caring for patients. Most care coordinators work with patients who have significant co-morbidities. Care coordinators need to be compassionate and possess basic communication and customer service skills. Employers reported that candidates should feel confident communicating across different sectors of clinical staff and be able to work within an interdisciplinary team. It is essential 
that candidates assist patients with articulating goals, teach them self-management techniques, and monitor their progress over time. Job seekers need to possess good computer and documentation skills and the ability to manage a case load using an electronic medical record system. Many employers stressed that care coordination is not currently offered as part of the curriculum at most colleges. Employers reported they would like to see care coordination competencies offered as part of the AS in Health Sciences Degree, which could include topics such as skills in care coordination, motivational interviewing, standards of care, and patient engagement. One participant suggested we could incorporate many of these core competencies by embedding care coordination curriculum that is recognized as agreed upon standards of training among health care employers in New York State (New York State Department of Health, 2016a).

\section{Theme 2: Population Health \& Health Administration Fields}

Two other in-demand fields reported by participants were population health and health administration. We chose to collapse these two categories into one, for the purposes of this paper, because they both focus on a systems-based approach and the use of information technology to help achieve long-term goals. The term population health is essentially how health care and social systems can work together in order to improve the health outcomes for the communities they serve (Milken Institute of Public Health, The George Washington University, 2015). For example, practitioners may see population health as their patient panel but it is also more broadly an approach that considers how the social determinants of health impact the health of a population (New York State Department of Health 2013b). Health administrators are generally responsible for the management of health care systems (Careers in Public Health, 2021). Entry level job titles in these areas include billing representative, unit secretary, clerk, program assistant and data manager. Most of these positions require at least a high school diploma with a certificate in medical coding and billing and/or information technology and some work experience. Employers also want candidates to possess knowledge of International Classification of Diseases (ICD-10) and current procedural or medical terminology.

Participants reported that employees in the population health field should be proficient in working with data, lists and cataloging. In particular, they are tasked with gathering data (such as creating lists of patients), assigning them to categories and interpreting what actions need to be taken to improve patient care. Employers noted that job candidates interested in working in health administration understand the insurance side of business and have customer service skills. Employers reported they would like to see the following topics embedded into the curriculum: project management skills, health science research skills, skills related to lay reporting of scientific terms, utilization review and management, basic terms on the payer side and computer skills. Participants stressed the importance of embedding certifications in information technology and/or medical coding or billing. Medical coding and billing jobs are in high demand but employers typically hire internal candidates. One hiring manager at the round table stated that if a person has some type of medical billing and coding certificate, they would be competitive against internal candidates, especially if they have ICD10 experience and/or training.

\section{Theme 3: Clinical Field}

Employers reported that clinical positions in areas such as medical lab technology, nuclear medicine, radiologic technology and nursing, especially certified nursing assistants, are in demand fields. A participant reported that certified nursing assistant positions are very in demand and hard to fill but they are good entry-level positions. Entry-level positions in these fields include clinical lab assistant, phlebotomist, certified nursing assistant, patient transport jobs, and patient care technician. Most of these positions require at least a high school diploma with some type of certificate in clinical care. Participants reported that those working on the clinical side should possess specimen processing, in some instances, and good communication skills. Employers suggested that the following types of certificates be included in a clinical track: phlebotomy, electrocardiogram, cardiopulmonary resuscitation and surgical technology. Several participants emphasized that these types of certifications are pathways into the clinical field. Students can work in a clinical position and gain the skills and experience they need, while they continue their education. 


\section{Theme 4: Employers' Qualification Preferences for All Candidates}

Employers reported that in all positions they prefer candidates with the following qualifications: handson experience, especially customer service experience, knowledge of a second language, and communication and professionalism skills. Participants reported they want candidates who are prepared for work whether that is through internships, services learning opportunities or simulation activities. However, employers reported they are sometimes reluctant to offer internship opportunities because of the liability and insurance coverage issues for students. In addition, some participants stated that their staff often does not have enough time to oversee students and consequently will not offer internships to students. A participant noted that what employers seem to value the most, in terms of hiring individuals, is first-hand experience working with clients. They want students to know how to handle situations with patients in a professional manner even if they are not being treated well by a patient. Several attendees mentioned that students should highlight any type of retail experience on their resumes because this type of experience shows they can interact with many types of customers.

Participants noted they want to hire candidates who have knowledge of a second language. A couple of participants reported that even if a student is not fluent in a second language, they should make it very clear on their resume what their level of knowledge is regarding the second language. Even if a candidate is not fluent in a second language, they can relate to patients and can connect in some way. Finally, attendees reported they are desperate to find candidates that have good communication and professionalism skills. They would like to see candidates who are articulate, can build relationships with co-workers, possess emotional intelligence, and are able to network and write fluently.

\section{DISCUSSION}

\section{Major Findings}

Our findings are consistent with major trends in the health care delivery system. On a national level, the health care industry is shifting away from a concentration on acute illness to an emphasis on primary and secondary prevention. More providers are beginning to work under a value-based payment system where they are being rewarded for better patient health outcomes and efficient delivery of care (Vogenberg $\&$ Santilli, 2019). Consequently, there is a growing use of approaches, such as the Patient-Centered Medical Home model, which provide a framework for the comprehensive care of patients. This model uses an interdisciplinary team-based approach to improve patient health outcomes (Primary Care Collaborative, 2015). It is in within this context that many of the job categories identified are emerging and are increasing in number.

In these interdisciplinary team-based models of care, practitioners are finding that care coordination is becoming increasingly necessary because of the high rates of chronic diseases and the fragmentation of the health care system (Friedman et. al., 2016). Care coordination is identified by the Institute of Medicine to have the potential to improve the effectiveness, safety, and efficiency of the health care system, thus helping to better manage those patients with chronic diseases (U.S. Department of Labor, 2018a). This has proven to be true in New York State where the most successful health care initiatives have relied on non-traditional and non-clinical workers, such as community health workers, peers, patient/community navigators, to achieve their project goals. These workers have been successful in helping clients navigate the clinical and social service systems to meet their unique needs. Thus, there is strong support in the state for health care systems to employ these types of value-adding workers over the long term (New York State Department of Health, 2019c).

There is also a continued nationwide focus on the use of population health to improve health outcomes (Vogenberg \& Santilli, 2019). Population health is one of the foundations of the Triple Aim Model developed by the Institute for Healthcare Improvement (2021). This model provides a structure for improving the individual experience of health care, and the health of populations, to improve care and reduce costs. It is a part of the US's national strategy for addressing health care inequities and is a widely used model throughout the healthcare delivery system (Whittington et. al., 2015). New York state supports the Triple Aim Model, and, as a strategy within this model, is calling for a sustained focus on the continued 
use of promising population health approaches, such as interventions around housing, nutrition and toxic stress, in order to reduce long term utilization and costs (New York State Department of Health, 2019d). Unquestionably, these types of interventions rely heavily on employing individuals who can think on a systems wide level and are trained in using information technology. The need for these workers will only grow as our health challenges increase and become more complex in the light of the COVID-19 pandemic.

Further, health administration and clinical fields, such as nursing and other non-physician pathways, are in high demand both nationally and in New York State. Of the 20 occupations in the US with the highest percent of projected change of employment between 2019-29, eight are health-related fields (U.S. Department of Labor, 2020a). In New York State between 2010 and 2016, the number of health care jobs increased by nearly $9 \%$, with the second highest growth in the New York City area. Some of the fields that saw substantial growth between 2008-2018 included home health aides, physician assistants, physical therapist aides, medical assistants, medical secretaries and medical records and health information technicians (New York State Department of Labor, 2018). For the foreseeable future, health administration and clinical positions will continue to be in high demand as our nation grapples with high health care costs, multiple payers and a fragmented delivery system.

Finally, it is not surprising that employers are having difficulty finding well-prepared students in the local area. Low-income students are often underprepared for college and need developmental support to succeed at college level work (Engle and Tinto, 2008). Hence, they often do not possess the communication and polished professional skills that are valued in the workforce. Further, although internships are widely seen as high impact practices among educators they are often out of reach for low-income students because of competing obligations, such as work and family responsibilities, that prevent them from participating in an internship, especially an unpaid internship (Hora, 2019).

\section{Curriculum Development}

Our plan to develop an AS in Health Sciences takes a holistic approach to preparing students for multiple career pathways in the health sector. It will be the only program of its kind to be offered in the Bronx, where health care is the largest employer (Office of the New York State Comptroller, 2018). In addition, it will be one of only a few programs in the New York City area to offer a concentration in care coordination within an academic program. The only program that we are aware of is at Silberman School of Social Work, Hunter CUNY (2020), which offers a care coordination track within its Bachelor of Social Work program. Given that we are creating an innovative degree program for our region, it has been invaluable to obtain employer participation and their recommendations have had a significant impact on the development of the degree. We have used many of their suggestions and combined them with recommendations from various stakeholders in the BCC community, and information about national and local trends regarding health science(s) degrees, to develop a detailed outline for the degree, which is described below.

\section{Program Overview and Goals}

The program will include embedded, industry-aligned, "stackable" certifications, thus giving students the opportunity to earn health-related certifications while they work toward an associate degree that prepares them for entry into a degree in a health field. The program's total degree requirements will be 60 credits and will include the following goals:

- Provide an academic home for the large number of students who intend to pursue admission to a licensed health-profession degree program such as nursing.

- Provide embedded, industry-aligned, "stackable" certifications that will increase students" ability to enter the health field prior to or immediately after they complete their associate degree.

- Prepare students for entry into a baccalaureate degree in a health field.

- Expose students, through curriculum-embedded career exploration, to health-related clinical and nonclinical majors at the certificate, associate and baccalaureate levels. 


\section{Basic Common Core}

The program will include a basic common core of required classes and major requirements. It will include embedded career exploration assignments, population health concepts-such as the social determinants of health- and prerequisite clinical classes options for various health majors. This is similar in concept to Rogue Community College's Basic Health Care Certificate (2021), which provides a cluster of centralized classes, with embedded health career exploration assignments, that students can use as a base to go in different health majors and career directions. By requiring a basic core in the AS in Health Sciences at $\mathrm{BCC}$, the program will create a clear path to allied health programs by accommodating the pre-clinical courses required for admission to nursing, radiologic technology, nuclear medicine technology, medical lab technician and other allied health degrees.

Certainly, many students will not meet admission requirements for clinical programs - or they might change their mind about what career to pursue. The AS in Health Sciences will serve these students through an embedded career exploration curriculum in the first semester to expose them to the many options in the health field both at the associate and baccalaureate levels. These students will have the opportunity to earn an AS in Health Sciences degree that will be related to their field of interest and prepare them for a baccalaureate degree in a health field. In addition, those students enrolled in the AS in Health Sciences, who find in their first semester through career exploration, that an AS in public health, therapeutic recreation, exercise and kinesiology, human services or medical office assistant is a better fit for them, can seamlessly switch majors after the first semester without losing credits and momentum.

\section{Three Tracks of Study With Embedded Certifications}

After completing the foundational requirements, students can choose to focus on one of three tracks of study including: 1) care coordination, 2) health administration or 3) pre-clinical. In each of these tracks we intend to embed certifications and in-demand competencies. These three areas of study were created as a direct result of the feedback we received from employers. We plan to give prior learning credit toward the degree for students who have completed the certificates outside of the College and/or through BCC's Workforce and Economic Development Department as continuing education classes. This type of structure is similar to how other colleges have organized their AS in Health Science(s) degrees. For example, the Community College of Baltimore County's Allied Health, Associate of Applied Science (2021) provides options for stackable credentials and permits students who have achieved national certificates, such as pharmacy technician and medical coding, to receive credit for prior learning toward the associate's degree. The degree also offers additional concentrations in the areas of management, leadership, communications. According to a recent Lumina Foundation report, some of the top benefits of embedding industry and professional certifications into curriculum is that students have the opportunity to complete professionally recognized certifications, it helps college curriculum stay up to date, and employers are able to have a pool of students trained to meet their specific workforce needs (Zanville et. al, 2017). Our proposed embedded certifications and in-demand competencies for the AS in Health Sciences Degree at BCC will include:

- A Cardiopulmonary Resuscitation (CPR) course in which students can earn the American Heart Association (2021) certification in CPR. This will be required of all AS Health Sciences students.

- A nationally recognized certification from the National Healthcare Association (2021) called the Certified Billing and Coding Specialist (CBCS), the competencies of which will be embedded in a newly created class within the health administration track.

- Electrocardiogram (EKG) and Phlebotomy courses in the pre-clinical track. After completing each of these classes, students will have the option to enroll in extension classes in BCC's Workforce and Economic Development Department to complete the remaining requirements to be able to earn two nationally recognized certifications from the National Healthcare Association (2021) called the Certified EKG Technician (CET) and The Phlebotomy Technician Certification (CPT). 
- In the care coordinator track, we will embed curriculum from the Guidelines for Core Curriculum to Train Care Coordinators that was developed by New York State's DSRIP State Innovation Model Workforce Workgroup (2016). The curriculum is for workers who provide care coordination services and it is strongly recommended for use statewide.

\section{Flexibility}

Another unique feature of the program will be its flexibility in course offerings and content. We plan to encourage faculty to use Open Educational Resources (Sparks, 2020) that include current industry-based material. We will also build in options to add elective and/or alternative course offerings, and plan to continually review current course learning objectives, to see if and where we can incorporate additional embedded certification options for students. For example, an additional certification we may consider for the clinical track is infection control training, which is approved by the New York State Department of Health. (2019e). This is a mandated training that all dentists, dental hygienists, licensed practical nurses, optometrists, podiatrists, and registered nurses must complete every four years to practice in the state and may be beneficial to students as they move forward with their careers. Another certification we could offer in the health administration track is the National Healthcare Association's (2021) Certified Electronic Health Record Specialist. As with the other certificates mentioned in the section above, all of these additional certificates could be offered through BCC's Workforce and Economic Development Department as continuing education classes as well. Students could use them as prior learning credits, thus accelerating their path to graduation.

\section{Experiential Learning Opportunities}

A further important component of the program will be its focus on experiential learning opportunities, which will allow us to embed a variety of culminating experiences into specific classes across the curriculum. We plan to embed diversified learning experiences into the curriculum that will include such activities as service-learning projects in collaboration with community partners, volunteer and internship hours earned across several courses, and the adoption of different aspects of simulated field experiences currently in use within other health-related fields. These experiential and applied learning opportunities reflect current initiatives at CUNY (2021) and are an important and growing part of the educational experience for students at the University. Studies have shown that experiential learning can be transformative for students and lead to increased rates of retention and engagement CUNY (2021). It will also help our students gain valuable work-related experience and serve as an important alternative avenue for those students who struggle to find time to invest in an internship experience. Experiential learning can also serve as a complement to an internship experience for those students who are able to complete one. Thus, we are able to address the issue, which was brought up by employers at the round table, that they may not be able to offer an internship but are looking for candidates with hands on experience.

\section{Communication and Professionalism Skills Embedded Across the Curriculum}

Additionally, we will focus on building communication and professionalism skills throughout the curriculum. We will work with BCC's Writing Across the Curriculum Department to embed written assignments as a way to think through and master course concepts as well as improve overall writing skills. Students will be required to complete two writing intensive courses before they graduate. As part of the basic core curriculum, students will also be strongly advised to take an interpersonal communication class. Finally, we will collaborate closely with BCC's student academic support and success programs, such as the writing center, library, tutoring services, advisors and career development office, to help students build skills that will be useful throughout their academic studies and careers. For instance, in some classes we are already embedding assignments that are focused on developing a resume, conducting job searches and participating in mock interviews. The majority of our students have some level of proficiency in a second language and will be encouraged to highlight this on their resumes. 


\section{Enhanced Academic Advisement \& Development of an Advisement Toolkit}

Finally, as part of the development of this new program, BCC is investing in academic advisement that is in line with the guided pathways approach (Bailey et al., 2015). Recently, BCC faculty, in coordination with Student Affairs and Transfer Services, began hosting health-related degree and career information sessions each semester as a way to inform students about all the health-related degree options available at BCC. Through these sessions BCC is seeking to educate students about all their options in an effort to help them make informed decisions before too much time is wasted in the pursuit of a degree that is not a good fit. As part of the orientations, faculty present overviews of their respective programs, including course requirements; career opportunities in the field and the associated average salaries; internship opportunities and information on advanced degree programs/articulation agreements with four-year colleges. Alumni of these programs and health professionals share their career and/or educational successes with students.

Additionally, the College is holding regular in-depth advisor training annually for all academic advisors on campus to provide detailed information about the programs they offer, including: course overviews; grade requirements (if applicable); career options across the fields, articulation agreements in place or in development with four-year colleges and scholarship opportunities. Employer partners are invited to these events and speak about opportunities for students. The information advisors learn from these sessions are incredibly valuable as they meet with students who are seeking guidance around which majors to pursue. As a means to ensure this information is readily available for advisors post-training, a toolkit is being developed to include all the presentations and related information shared during the trainings. Once compiled, the toolkit will be centrally housed for any-time access by all advisors through the College's website. The toolkit will also contain a list of free online resources, including O'Net, a career exploration website sponsored by the U.S. Department of Labor (2020b) and their O'Net Interest Profiler, which is a quick assessment that advisors can direct students to use to help them decide which careers they would like to explore. Further, we will gather online videos of professionals in different health careers who share their experiences across these types of topics: work environment, a day in the life of their job, how they got there, the industry culture, barriers, their likes/dislikes, and what they wish they knew in college. All advisors will be trained on how to use this toolkit as part of their professional development.

\section{Next Steps}

Our immediate next steps are to continue to refine the curriculum and share it with employers for further feedback. We plan to create an employer advisory board so that we have a formal structure where we can continue to seek industry-based advice and guidance. Employers' participation will be invaluable in helping us stay up to date on current trends in the local health care workforce and the continued development of course offerings, competencies and certifications for the program. Next, we plan to work on securing various articulation agreements for programs with senior colleges within CUNY and the New York city area. We will also investigate how we can assist students in paying the fees associated with obtaining the certifications. Perhaps, we may be able to secure grant funding through private or public sources. Lastly, we will prepare the full proposal for the review process, which will include review by the BCC Curriculum Committee, the CUNY Board of Trustees and, ultimately, the New York State Department of Education.

We hope that our model can be replicated for other related majors throughout the College such as business, technology, STEM related majors, education and liberal arts. One of our institutional goals is to move toward meta-majors and continue and expand upon guided academic and career pathways for all students. Many of our majors have industry certification options that can be embedded in their curriculum as well earned through BCC's Department of Workforce and Economic Development or elsewhere for college credits earned upon matriculation. The development of this degree could provide a roadmap for others at the College who may want to develop similar stackable credit pathways. Creating stackable degree programs across the College could have a considerable impact on increasing our students' upward mobility. Further, if successful, we will share our model more broadly, within CUNY, and with other institutions within the area. 


\section{CONCLUSION}

This paper reported on how faculty and staff at BCC obtained feedback from local health care employers to inform the development of an AS in Health Sciences degree program. The paper discussed the implementation process of an employer roundtable session, the relevant themes that arose during the session, and how these finding are being used to create a degree program that is responsive to local workforce needs.

Results indicate that three growing fields within the local Bronx health care sector are care coordination, population health/health administration and careers in clinical health. Employers also identified their preferred skills for job applicants including some type of work-experience, knowledge of a second language and communication and professionalism skills. Our team is currently using the feedback provided by employers to help inform the development of the degree. The AS in Health Sciences will be responsive to local workforce needs and it will also serve the needs of our students by providing them with a pathway to meaningful careers in the health care field. It is our hope that our model can be used by others to create stackable credential pathways for their students.

\section{ACKNOWLEDGMENTS}

We would like to thank Graduate NYC for generously funding our project and the BCC faculty and staff who are working with us to develop this degree program.

\section{REFERENCES}

American Association of Colleges of Nursing. (2020, September). Fact sheet: Faculty nursing shortage. Retrieved from https://www.aacnnursing.org/Portals/42/News/Factsheets/Faculty-ShortageFactsheet.pdf

American Heart Association. (2021). American heart association CPR \& first aid. Retrieved from https://cpr.heart.org/en

Bailey, T., Jaggars, S.S., \& Jenkins, D. (2015). What we know about guided pathways. New York, NY: Columbia University, Teachers College, Community College Research Center. Retrieved from https://ccrc.tc.columbia.edu/publications/what-we-know-about-guided-pathways-packet.html

Baker, R., Bettinger, E., Jacob, B., \& Marinescu, I. (2017). The effect of labor market information on community college students' major choice. Education Policy Initiative, pp. 1-66. Working paper No. 02-2017. Ann Arbor, MI: Gerald R. Ford School of Public Policy. Retrieved from https://www.edpolicy.umich.edu/files/02-2017-labor-market-major-choice.pdf

Bond, D. (2013). Engaging employer to support adult career pathways programs (Issue Brief). Designing Instruction for Career Pathways (DICP) Initiative, Kratos Learning in partnership with the Center for Occupational Research and Development. Retrieved from https://lincs.ed.gov/publications/pdf/acp/Engaging_Employers_IssueBrief.pdf

Borough of Manhattan Community College. (n.d.). Science for health professions. Retrieved from https://www.bmcc.cuny.edu/academics/departments/science/science-for-health-professions/

Bronx Community College. (2020, January 31). Facts \& figures. Retrieved from http://www.bcc.cuny.edu/about-bcc/facts-figures/

Buerhaus, P.I., Auerbach, D.I., \& Staiger, D.O. (2016). Recent changes in the number of nurses graduating from undergraduate and graduate programs. Nursing Economics, 34(1), 46-48.

Causey, J., Huie, F., Lang, R., Ryu, M., \& Shapiro, D. (2020, December). Completing college 2020: A national view of student completion rates for 2014 entering cohort (Signature Report 19). Herndon, VA: National Student Clearinghouse Research Center.

Careers in Public Health. (2021). What is public health administration? Retrieved from https://www.careersinpublichealth.net/resources/what-public-health-administration/ 
City University of New York. (2021). Experiential Learning. Retrieved from https://www.cuny.edu/academics/current-initiatives/experiential-learning/

Community College of Baltimore County. (2021). Allied Health, Associate of Applied Science. Retrieved from http://www.ccbcmd.edu/Programs-and-Courses-Finder/Program/allied-health

Community College Research Center. (2021). Community college FAQs. Retrieved from https://ccrc.tc.columbia.edu/Community-College-FAQs.html

Delivery System Reform Incentive Payment/State Innovation Model Workforce Workgroup. (2016). Guidelines for core curriculum to train care coordination worker (pp. 1-33). New York, NY: New York State Department of Health. Retrieved from https://www.health.ny.gov/technology/innovation_plan_initiative/docs/core_curriculum_train_cc w.pdf

Department of Health and Human Services. (2018, August). Care coordination. Agency for Healthcare Research and Quality. Retrieved from https://www.ahrq.gov/ncepcr/care/coordination.html

Engle, J., \& Tinto, J. (2008). Moving beyond access: College success for low-income, first-generation students. Washington, DC: The Pell Institute. Retrieved from http://www.pellinstitute.org/downloads/publications-Moving_Beyond_Access_2008.pdf

Friedman, A., Howard, J., Shaw, E.K., Cohen, D.J., Shahidi, L., \& Ferrante, J.M. (2016). Facilitators and barriers to care coordination in patient-centered medical homes (PCMHs) from coordinators' perspectives. Journal of the American Board of Family Medicine: JABFM, 29(1), 90-101. https://doi.org/10.3122/jabfm.2016.01.150175

Graduate NYC. (2016). College readiness \& success. Retrieved from http://www.graduatenyc.org/

Gardenhire-Crooks, A., Collado, H., \& Ray, B. (2006). A whole 'nother world students navigating community college (pp. 1-57, Rep.). New York, NY: Manpower Demonstration Research Corporation. Retrieved from https://www.mdrc.org/sites/default/files/OD_A_Whole\%20_Nother_World_0.pdf

Haynie, D. (2015, June). Prepare for stiff competition to get an associate degree in nursing. U.S. News and World Report. Retrieved from https://www.usnews.com/education/communitycolleges/articles/2015/06/10/prepare-for-stiff-competition-to-get-an-associate-degree-in-nursing

Hu, W., Corona, J., \& Kim, J. (2020, December). 'It makes me angry': These are the jobless in a city filled with wealth. New York Times. Retrieved from https://www.nytimes.com/2020/12/07/nyregion/bronx-unemployment-covid.html

Hora, M. (2019, September). Internships as a high-impact practice? Retrieved from https://www.insidehighered.com/views/2019/09/23/campuses-should-proceed-caution-when-itcomes-student-internships-opinion

Institute for Healthcare Improvement. (2021). Triple aim for populations. Retrieved from http://www.ihi.org/Topics/TripleAim/Pages/Overview.aspx

Jenkins, D., \& Cho, S.W. (2012). Get with the program: Accelerating community college students' entry into and completion of programs of study. (CCRC Working Paper No. 32). New York, NY: Columbia University, Teachers College, Community College Research Center. Retrieved from $\mathrm{https} / / / \mathrm{ccrc} . t c . c o l u m b i a . e d u / m e d i a / \mathrm{k} 2 /$ attachments/accelerating-student-entry-completion.pdf

Lumina Foundation. (2019). A stronger nation: Learning beyond high school builds American talent (Rep.). Retrieved from https://www.luminafoundation.org/stronger-nation/report/2020/\#nation

Martiniano, R., \& Moore, J. (2018, February). Health care employment projections, 2016-2026: An analysis of bureau of labor statistics projections by setting and by occupation. Rensselaer, NY: Center for Health Workforce Studies, School of Public Health, SUNY Albany. Retrieved from https://www.chwsny.org/our-work/reports-briefs/analysis-of-bureau-of-labor-statisticsprojections-by-setting-and-by-occupation/

Milken Institute of Public Health. (2015, April 27). What is population health? The George Washington University. Retrieved from https://onlinepublichealth.gwu.edu/resources/what-is-populationhealth/ 
Mintz, S. (2020, July). Why it's so difficult to get into nursing programs. Retrieved from https://www.insidehighered.com/blogs/higher-ed-gamma/why-it $\% E 2 \% 80 \% 99$ s-so-difficult-getnursing-programs

National Center for Education Statistics. (2019). Digest of education statistics. Retrieved from https://nces.ed.gov/programs/digest/d19/tables/dt19_321.30.asp

National Healthcare Association. (2021). Allied Health Certification. Retrieved from https://www.nhanow.com/certification

National Student Center Clearing House Research Center. (2020). COVID-19: Stay informed with the latest enrollment data. Retrieved from https://nscresearchcenter.org/stayinformed $/$ hilite $=\% 27$ covid $\% 27 \% 2 \mathrm{C} \% 2719 \% 27$

New York State Department of Health. (2020). Delivery system reform incentive payment (DSRIP) program. Retrieved from https://www.health.ny.gov/health_care/medicaid/redesign/dsrip/

New York State Department of Health. (2016a, December). Care coordination essentials to transform existing roles in healthcare. Retrieved from

https://www.health.ny.gov/health_care/medicaid/redesign/dsrip/pps_workshops/2016-0621_care_coordination_essentials.htm

New York State Department of Health. (2013b). Making New York the healthiest state: Achieving the triple aim population health summit. Retrieved from https://www.health.ny.gov/events/population_health_summit/docs/what_is_population_health.pd $\mathrm{f}$

New York State Department of Health. (2019c, September). Medicaid redesign team 1115 waiver amendment update. Retrieved from https://www.health.ny.gov/health_care/medicaid/redesign/dsrip/2019/amendment_req.htm

New York State Department of Health. (2016d, September). A plan to transform the empire state's Medicaid program. Retrieved from https://www.health.ny.gov/health_care/medicaid/redesign/mrtfinalreport.htm\#redesign

New York State Department of Health. (2019e). Health care provider infection control training. Retrieved from https://www.health.ny.gov/professionals/diseases/reporting/communicable/infection/hcp_training. htm

New York State Department of Labor. (2020, November). Rate of unemployment by county of residence New York State. Retrieved from https://www.labor.ny.gov/stats/PressReleases/county_rates.pdf

New York State Department of Labor. (2018a). Fastest growing occupations. Retrieved from https://www.labor.ny.gov/stats/demandf.asp?reg=

Office of the New York State Comptroller. (2018, July). An economic snapshot of the Bronx (Rep.). Retrieved from https://www.osc.state.ny.us/files/reports/osdc/pdf/report-4-2019.pdf

Ott, A. (2018, October). Academic master plan of Bronx Community College of the City University of New York: 2018-2023. Retrieved from http://www.bcc.cuny.edu/wpcontent/uploads/2018/10/amp-v10-31-18.pdf

Primary Care Collaborative. (2015, September). Patient-centered medical home: What is a patientcentered medical home (PCMH)? Retrieved from https://www.pcpcc.org/resource/patientcentered-medical-home-what-patient-centered-medical-home-pcmh

Rogue Community College. (2021). Allied Health, Associate of Applied Science. Retrieved from http://www.ccbcmd.edu/Programs-and-Courses-Finder/Program/allied-health

Scott-Clayton, J. (2011). The shapeless river: Does a lack of structure inhibit students' progress at community colleges? (CCRC Working Paper No. 25, Assessment of Evidence Series). New York, NY: Columbia University, Teachers College, Community College Research Center. Retrieved from https://ccrc.tc.columbia.edu/media/k2/attachments/shapeless-river.pdf

Silberman School of Social Work, Hunter, CUNY. (2020, November 23). Bachelor of Social Work. Retrieved from https://sssw.hunter.cuny.edu/programs/bsw/ 
Sparks, S. (2020, December 11). Open educational resources (OER): Overview and definition. Retrieved from https://www.edweek.org/teaching-learning/open-educational-resources-oer-overview-anddefinition/2017/04

Trofino, R. (2013). Relationship of associate degree nursing program criteria with NCLEX-RN success: What are the best predictors in a nursing program of passing the NCLEX-RN the first time? Teaching and Learning in Nursing, 8(1), 4-12. doi: https://doi.org/10.1016/j.teln.2012.08.001

U.S. Department of Health and Human Services. Health Resources and Services Administration. (2020, December). What is shortage designation? Retrieved from https://bhw.hrsa.gov/workforceshortage-areas/shortage-designation

U.S. Department of Health and Human Services. Agency for Healthcare Research and Quality. (2018a, August). Care coordination. Retrieved from https://www.ahrq.gov/ncepcr/care/coordination.html

U.S. Department of Labor. Bureau of Labor Statistics. (n.d.). Occupational outlook handbook, registered nurses. Retrieved from https://www.bls.gov/ooh/healthcare/registered-nurses.htm

U.S. Department of Labor. Bureau of Labor Statistics. (2020a, September 1). Fastest growing occupations: Occupational outlook handbook. Retrieved from https://www.bls.gov/ooh/fastestgrowing.htm

U.S. Department of Labor. (2020b, November). Build your future with $O^{*} N E T$ onLine. Retrieved from https://www.onetonline.org/

Vogenberg, F.R., \& Santilli, J. (2019). Key trends in healthcare for 2020 and beyond. American Health \& Drug Benefits, 12(7), 348-350.

Whittington, J.W., Nolan, K., Lewis, N., \& Torres, T. (2015) Pursuing the triple aim: The first 7 years. Milbank Q., 93(2), 263-300. doi: 10.1111/1468-0009.12122. PMID: 26044630; PMCID: PMC4462878.

Zanville, H., Porter, K., \& Ganzglass, E. (2017). Connection Credentials (pp. 1-17, Rep.). Lumina Foundation. Retrieved from https://www.luminafoundation.org/files/resources/report-on-phase-istudy-embedding-industry-professional-certifications-within-higher-education-january-2017.pdf 